\title{
External Quality Assurance in Immunohistochemistry - Is It the Solution to a Complex Problem?
}

\author{
Angelika Reiner-Concin \\ Dept. of Pathology, Donauspital, Vienna, Austria
}

In recent years testing of biomarkers for breast cancer was introduced into the routine diagnostic procedure in histopathology. Particularly testing for steroid hormone receptors and HER2 has become an important issue due to the prognostic importance of these factors and more importantly due to the predictive value with respect to anticancer therapeutics.

Antihormonal therapy has been applied for almost three decades in adjuvant therapy in breast cancer and is widely accepted as a standard therapy. Selection of patients for antihormonal therapy relied for many years on testing of frozen tissue, as in the beginning it consisted of a biochemical hormone binding assay. This test relied on binding of radioactively labeled estrogen or progesterone to the receptor in homogenized tumor tissue. Naturally it was not possible to discriminate whether a positive result was due to receptor localization within tumor tissue or due to contamination of benign parenchymal components entrapped within the tumor or deriving from the vicinity of the tumor. On the other hand in case of a negative test result it could not be ruled out for certain whether tumor samples tested contained large fibrotic or necrotic areas mimicking steroid receptor negativity while the tumor itself truly would have been receptor positive. Therefore much effort was put into development of immunohistochemical tests that would allow direct visualization of steroid hormone receptors within the tumor cells. The first immunohistochemical tests used frozen sections [1]. This held the advantage of causing only minor artefacts with regard to applied chemicals. However, frozen sections were found to be fragile and handling troublesome. The consequence was further development of immunohistochemical tests for steroid hormone receptors on paraffin sections. These assays were introduced into routine diagnostic procedures during the 1990s.

For HER2, an important predictive marker for response to several therapeutic options in breast cancer patients, testing has been established preferably also on paraffin sections. Particularly the invention of targeted therapies e.g. the humanized anti-HER2 monoclonal antibody trastuzumab has made correct assessment a crucial issue. Assessment is recommended by the ASCO/CAP guidelines in every invasive breast can- cer [2]. Correct test results are crucial because due to incorrect assessment not all patients may receive appropriate therapies. Patients with false negative results may be denied an effective therapy and patients with false positive assessment may be exposed to unnecessary side effects and wrong expectations will be raised. Thus, reliable diagnostic tests are necessary and quality assurance is urgently needed.

It was thought that using paraffin embedded samples would solve existing problems. But the use of formalin fixed paraffin embedded tissue for testing has raised problems as well and today we still deal with limitations. However, these are different from the trouble we had with frozen material. The most important issue is formalin fixation of tissue itself. Formalin is used for tissue fixation since the earliest days of histology. But its mechanism is still not quite clear. It has been thought to work by cross-linking amino groups to adjacent molecules with formation of bridging links. It is known that a critical minimal and maximal duration for fixation exists in order to achieve proper results in immunohistochemistry. Both too short and prolonged tissue fixation may lead to false negative immunohistochemical results. Too short fixation may result in a mixture of formalin and ethanol fixation. This means that sufficient formalin fixation takes place only at the periphery of the tissue block. In the center of the block coagulation of proteins is caused by the following step of tissue processing i.e. tissue dehydration. As a result of incomplete fixation autolytic changes are found and test results are falsely negative. On the other hand prolonged fixation may result in only weak or even absent staining due to excessive crosslinking of proteins resulting in hidden epitopes [3]. Proper fixation time is accepted to lie between 24 and $48 \mathrm{~h}$. Another issue is delayed formalin fixation causing autolytic changes in the tissue and it is recommended that fixation should be started within 30 min after surgical removal.

The second issue is tissue processing. This is performed after fixation and today automated devices are used. The main goal is tissue dehydration in order to prepare the sample for paraffin embedding. To guarantee consistent quality of this step of preparation it is prudent to define standard laboratory procedures, including exchange of dehydration reagents after a de-

\begin{tabular}{|c|c|}
\hline KARGER & (c) 2008 S. Karger GmbH, Freiburg \\
\hline $\begin{array}{l}\text { Fax }+497614520714 \\
\text { E-mail Information@Karger.de } \\
\text { www.karger.com }\end{array}$ & $\begin{array}{l}\text { Accessible online at: } \\
\text { www.karger.com/brc }\end{array}$ \\
\hline
\end{tabular}


fined maximum of tissue volume has been treated with one lot of reagents.

Particularly high effort has been put in solving the problem of excessive crosslinking caused by formalin fixation. It is now widely accepted that so-called antigen retrieval procedures (applying heat to the samples) result in unmasking of epitopes. Application of this step is crucial for achieving correct immunohistochemical results. Altogether the described process includes several critical steps in laboratory performance which may result in variability and influence sensitivity and specificity of biomarker assays. Several of these steps take place even prior to the immunohistochemical staining procedure and are usually not part of an external quality assurance program.

In addition, assay results also depend on correct microscopic interpretation and inter- and intraobserver variability for steroid hormone receptors and HER2 have been described. Traditionally immunohistochemistry is assessed qualitatively, which is a decision between staining present or not present. For assessment of predictive parameters for breast cancer quantitative analysis is performed by scoring. This is a rather new and challenging issue.

Because awareness of these problems has risen in recent years several initiatives for external quality assurance programs have been started. Besides the well known programs run by the UK NEQAS and NordiQC an initiative of Germany (QuIP) is described in this issue of BREAST CARE by von Wasielewksi et al. [4]. Also in other countries, e.g. Austria, similar programs were introduced $[5,6]$. Such programs are very ambitious and laborious and questions regarding these programs are discussed thoroughly in the paper.

A major question is definition of a gold standard for setting the benchmark discriminating between failure and success. Conventionally when testing a strategy, validation is performed by comparing an established test with a new strategy. This approach is not necessarily appropriate for assessing individual performance. For assessment of HER2 status usually in situ hybridization performed by either fluorescence or chromogenic assessment of gene amplification at the DNA level is recommended by guidelines as the gold standard. But the situation for assessment of steroid hormone receptors is different. No alternative laboratory assay exists since the biochemical assays on frozen tissue have been abandoned. Therefore solutions for defining a gold standard are sought by several strategies, however, with inherent limitations.

Von Wasielewksi et al. [4] describe definition of tissue test samples as gold standards as a rather complex process. Three expert laboratories select breast cancer tissues. Test samples need to result in identical testing in all three laboratories to be entered into the final slide circulation to participants. The identical result assessed by the expert laboratories defines the gold standard supporting benchmarking. But this process does not guarantee accuracy of assay results completely. In another approach widely used in quality assurance programs cell lines are introduced as gold standard [7]. Advantages of this approach lie in the evaluation of whole cells rather than tissue sections. Thus, artifacts of tissue fixation and processing are reduced in comparison with tissue samples. But cell lines, even when paraffin embedded, do not reflect staining in the real world of pathology.

The authors [4] also state that most trials focus on laboratory performance rather than microscopic evaluation of results. Therefore central reevaluation by expert pathologists was performed. This is a very useful instrument for providing feedback to participants in order to support improvement of laboratory procedures when needed. But as intra- and interobserver variability is known to occur also with experts it is not clear how to deal with variability in the reviewing process. Usually it is described for reviewing processes that in case of discrepancies pathologists with different opinions have to reach consensus at the microscope. Such strategies to my opinion do not result in a convincing test result but rather in a compromise. These concerns notwithstanding, von Wasielewksi et al. have discussed the approach of quality assurance initiatives and particularly the approach in Germany thoroughly and critically. Such programs are urgently needed to improve quality in a multiinstitutional approach and reduce variability of assay results between different laboratories. Several guidelines [8] strongly recommend participation of laboratories in such quality assurance programs if they perform assays for selection of patients for therapeutical options. As discussed, several problems limit the ambitious approach of quality assurance in immunohistochemistry. No simple answers can be expected for future solutions of this complex problem.

\section{References}

1 Greene GL, Fitch FW, Jensen EV: Monoclonal antibodies to estrophilin: probes for the study of estrogen receptors. Proc Natl Acad Sci U S A 1980;77: $157-161$.

$\checkmark 2$ Wolff AC, Hammond ME, Schwartz JN, Hagerty KL, Allred DC, Cote RJ, Dowsett M, Fitzgibbons PL, Hanna WM, Langer A, McShane LM, Paik S, Pegram MD, Perez EA, Press MF, Rhodes A, Sturgeon C, Taube SE, Tubbs R, Vance GH, van de Vijver M, Wheeler TM, Hayes DF: American Society of Clinical Oncology/College of American Pathologists guideline recommendations for human epidermal growth factor receptor 2 testing in breast cancer. Arch Pathol Lab Med 2007;131:18-43.

$\checkmark 3$ Werner M, Chott A, Fabiano A, Battifora H: Effect of formalin tissue fixation and processing on immunohistochemistry. Am J Surg Pathol 2000;24:10161019.
4 von Wasielewski R, Krusche CA, Rüschoff J, Fissler-Eckhoff A, Kreipe H: Implementation of external quality assurance trials for immunohistochemically determined breast cancer biomarkers in Germany. Breast Care 2008;2: DOI: 10.1159/000121885.

5 Regitnig P, Reiner A, Dinges HP, Höfler G, MüllerHolzner E, Lax SF, Obrist P, Rudas M, Quehenberger F: Quality assurance for detection of estrogen and progesterone receptors by immunohistochemistry in Austrian pathology laboratories. Virchows Arch 2002;441:328-334.

6 Reiner-Concin A, Regitnig P, Dinges HP, Höfler G, Lax S, Müller-Holzner E, Obrist P, Rudas M: Practice of HER-2 immunohistochemistry in breast carcinoma in Austria. Pathol Oncol Res, submitted for publication.
7 Rhodes A, Borthwick D, Sykes R, Al-Sam S, Paradiso A: The use of cell line standards to reduce HER-2/neu assay variation in multiple European cancer centers and the potential of automated image analysis to provide for more accurate cut points for predicting clinical response to trastuzumab. Am J Clin Pathol 2004;122:51-60.

8 Bilous M, Dowsett M, Hanna W, Isola J, Lebeau A, Moreno A, Penault-Llorca F, Rüschoff J, Tomasic G, van de Vijver M: Current perspectives on HER2 testing: a review of national testing guidelines. Mod Pathol 2003;16:173-182. 